\title{
Association Between Coping Strategies and Pain-Related Outcomes Among Individuals with Chronic Orofacial Pain
}

\author{
Jonathan Greenberg $\mathbb{D}^{1-3}$, Jafar Bakhshaie $\mathbb{D}^{1-3}$, Brenda C Lovette $\mathbb{D}^{3,4}$, Ana-Maria Vranceanu $\mathbb{D}^{1-3}$ \\ IIntegrated Brain Health Clinical and Research Program, Department of Psychiatry, Massachusetts General Hospital, Boston, MA, USA; ${ }^{2}$ Harvard \\ Medical School, Boston, MA, USA; ${ }^{3}$ Center for Health Outcomes and Interdisciplinary Research (CHOIR), Department of Psychiatry, Massachusetts \\ General Hospital, Boston, MA, USA; ${ }^{4} \mathrm{MGH}$ Institute of Health Professions, Boston, MA, USA
}

Correspondence: Jonathan Greenberg, Integrated Brain Health Clinical and Research Program \& Center for Health Outcomes and Interdisciplinary Research (CHOIR), Department of Psychiatry, Massachusetts General Hospital / Harvard Medical School, One Bowdoin Square, Ist Floor, Suite I06, Boston, MA, 02114, USA, Email jgreenberg5@mgh.harvard.edu

Background: Chronic orofacial pain is associated with substantial pain-related disability and emotional distress. Understanding the relationship between individuals' coping strategies and pain-related outcomes is important yet understudied in this population.

Purpose: To test the cross-sectional association of three coping strategies (pain catastrophizing, kinesiophobia and mindfulness) to four pain-related outcomes (depression, anxiety, pain intensity, and pain-related disability) among individuals with chronic orofacial pain, after accounting for relevant demographic and clinical variables.

Methods: Individuals ( $\mathrm{N}=303$ ) with heterogeneous chronic orofacial pain (eg, trigeminal neuralgia, other trigeminal neuropathic pain, persistent idiopathic facial pain and other types) completed self-report measures of coping (Pain Catastrophizing Scale, Tampa Scale of Kinesiophobia, and the 15-item Five Facet Mindfulness Questionnaire), pain intensity and pain-related disability (Graded Chronic Pain Scale), and PROMIS measure of anxiety and depression. We conducted 4 two-step hierarchical regressions for each of the four painrelated and emotional outcomes, with the first step including demographic and clinical covariates, and the second step including the three coping variables together.

Results: Pain catastrophizing was the only coping variable significantly associated with pain intensity $(\mathrm{B}=0.362, \mathrm{SE}=0.115, \mathrm{p}=0.002$, $3 \%$ variance explained) and pain-related disability ( $\mathrm{B}=0.813, \mathrm{SE}=0.162, \mathrm{p}<0.001,7 \%$ variance explained). Pain catastrophizing $(B=0.231-0.267, S E=0.046-0.051-0.050, p<0.001)$, kinesiophobia $(B=0.201-0.316, S E=0.081-0.084, p<0.001-0.018)$, and mindfulness $(B=0.231-0.306, S E=0.046-0.067, p<0.001)$ were each independently associated with symptoms of anxiety and depression, with the largest incremental variance added by catastrophizing (5-8\%) and mindfulness $(5 \%)$.

Conclusion: Pain catastrophizing appears to be an important intervention target to improve pain intensity, pain-related disability, anxiety and depression among individuals with chronic orofacial pain. Kinesiophobia and mindfulness may be additional treatment targets for interventions to improve anxiety and depression.

Keywords: chronic orofacial pain, coping, pain-related disability, anxiety, depression

\section{Introduction}

Chronic orofacial pain - pain in the face, mouth or jaw that is present for at least 1 day in the past month and spans at least 3 months ${ }^{1,2}$ - is common, ${ }^{3}$ and associated with high health care costs, ${ }^{4}$ substantial disability ${ }^{4}$ and emotional distress. ${ }^{12-14}$ Consistent with the growing conceptualization of chronic orofacial pain through a biopsychosocial perspective, ${ }^{5-9}$ psychological factors receive increasing empirical attention as key outcomes. Such psychosocial emphasis is evident across orofacial diagnostic categories, ${ }^{10-12}$ including musculoskeletal (eg, temporomandibular disorders ${ }^{13}$ ), neuropathic (eg, trigeminal neuropathic pain ${ }^{14}$ ), neurovascular (eg, migraine ${ }^{15}$ ), and other types of orofacial pain. ${ }^{16}$

Prior research among people with chronic pain has shown that coping strategies have a strong association with disability and emotional distress (symptoms of depression and anxiety). ${ }^{17-20}$ In particular, pain catastrophizing (a 
tendency to magnify pain, actively ruminate on it, and feel helpless about the pain experience ${ }^{21}$ ), kinesiophobia (excessive and debilitating fear of movement and activity due to pain or concerns about reinjury ${ }^{22}$ ), and mindfulness (paying attention on purpose, in the present moment, and non-judgmentally ${ }^{23}$ ). have shown strong associations with pain intensity, disability and emotional distress in patients with chronic pain. ${ }^{24-34}$ Although prior research has shown that pain catastrophizing and kinesiophobia are important among people with pain associated with temporomandibular disorders, ${ }^{35-42}$ these factors remain underexplored within other chronic orofacial pain conditions. ${ }^{43}$ Further, no research has explored the association between mindfulness and pain-related outcomes in chronic orofacial pain. Given that orofacial pain conditions tend to be comorbid ${ }^{44,45}$ and may share psychosocial processes, ${ }^{43}$ assessing these coping variables in individuals with heterogeneous chronic orofacial pain may help develop interventions for this population that are scalable and implementable.

Building on prior research, we conduct the first examination of the relationship between individuals' strategies for coping with their chronic orofacial pain (pain catastrophizing, kinesiophobia, and mindfulness), and pain-related outcomes (depression, anxiety, pain intensity, and pain-related disability) across a sample of people with heterogeneous chronic orofacial pain. We hypothesized that all three coping strategies would be significantly associated with depression, anxiety, pain intensity, and pain-related disability.

\section{Methods}

\section{Participants and Procedures}

We recruited individuals with chronic orofacial pain between March and June of 2021, through an electronic newsletter sent to members of the Facial Pain Association (FPA), a non-profit organization serving individuals with orofacial pain. Inclusion criteria were ages 18+, self-reported ability to read and write in English at a sixth grade level, having nonmalignant facial pain of any kind for more than 3 months, and living in the United States. Three-hundred fifty-five individuals indicated consent for participation on an electronic consent form presented prior to the questionnaires (see Table 1 for demographic and clinical characteristics). Of these, 303 subsequently completed the questionnaires on REDCap. All study procedures were approved by the Massachusetts General Hospital Institutional Review Board and were conducted in accordance with the Declaration of Helsinki. We classified reported diagnoses in line with the International Classification of Orofacial Pain, first edition (ICOP). ${ }^{46}$

Table I Demographics of the Participants $(\mathrm{N}=303)$

\begin{tabular}{|c|c|}
\hline \multicolumn{2}{|l|}{ Variable } \\
\hline Age, M (SD) & $59.11(27.57)$ \\
\hline \multicolumn{2}{|l|}{ Gender, n (\%) } \\
\hline Male & $42(13.9)$ \\
\hline Female & $26 I(86.1)$ \\
\hline \multicolumn{2}{|l|}{ Education, n (\%) } \\
\hline Less than high school & $2(0.7)$ \\
\hline High school & $31(10.2)$ \\
\hline Some college & $80(26.4)$ \\
\hline 4-year college & $95(31.4)$ \\
\hline Graduate/professional & $94(31)$ \\
\hline \multicolumn{2}{|l|}{ Employment status, n (\%) } \\
\hline Full time & $83(27.1)$ \\
\hline Part time & $36(11.6)$ \\
\hline Homemaker & $12(4)$ \\
\hline Student & $2(0.7)$ \\
\hline Unemployed & $118(38)$ \\
\hline Retired & $31(10.2)$ \\
\hline Other & $22(7.3)$ \\
\hline
\end{tabular}

(Continued) 
Table I (Continued).

\begin{tabular}{|c|c|}
\hline \multicolumn{2}{|l|}{ Variable } \\
\hline Marital status & \\
\hline Single & $29(9.6)$ \\
\hline Living $\mathrm{w} /$ significant other & $17(5.6)$ \\
\hline Separated/divorced & $32(10.6)$ \\
\hline Widowed & $12(4)$ \\
\hline \multicolumn{2}{|l|}{ Ethnicity, n (\%) } \\
\hline Hispanic/Latino & $16(5.3)$ \\
\hline Non-Hispanic/Latino & $274(90.4)$ \\
\hline \multicolumn{2}{|l|}{ Diagnostic category, n (\%) } \\
\hline \multicolumn{2}{|l|}{ Neuropathic } \\
\hline Trigeminal Neuralgia & $156(51.5)$ \\
\hline TNP & $22(7.3)$ \\
\hline TN2 & $22(7.3)$ \\
\hline PIFP & $16(5.3)$ \\
\hline \multicolumn{2}{|l|}{ Other } \\
\hline Multiple diagnoses & $60(19.8)$ \\
\hline Other & $14(4.6)$ \\
\hline None stated & $13(4.3)$ \\
\hline \multicolumn{2}{|l|}{ Pain duration, n (\%) } \\
\hline $0-I$ year & $14(4.6)$ \\
\hline $\mathrm{I}-5$ years & $70(23.1)$ \\
\hline $5-10$ years & $80(26.4)$ \\
\hline $10+$ years & $139(45.8)$ \\
\hline \multicolumn{2}{|l|}{ Mental health history, $\mathrm{n}(\%)$} \\
\hline None & $166(54.8)$ \\
\hline Depression & $96(31.7)$ \\
\hline Anxiety & 81 (26.7) \\
\hline PTSD & $29(9.6)$ \\
\hline Other & $15(5)$ \\
\hline Using pain medications, $\mathrm{n}(\%)$ & $216(71.3)$ \\
\hline Using mood medications, $\mathrm{n}(\%)$ & $103(34)$ \\
\hline
\end{tabular}

Notes: Diagnosis codes: $\mathrm{TNP}=$ Other trigeminal neuropathic pain $\mathrm{TN} 2=$ Classical trigeminal neuralgia with concomitant continuous pain Formerly: Atypical trigeminal neuralgia; trigeminal neuralgia type 2 PIFP= Persistent Idiopathic Facial Pain Formerly: atypical facial pain. Unlisted diagnoses included under "multiple diagnoses" and "Other" include migraines $(n=8)$, myofascial orofacial pain $(n=2)$, temporomandibular disorders $(n=7)$, glossopharyngeal neuralgia $(n=10)$, Hemicrania continua $(n=I)$, Burning Mouth Syndrome $(N=4)$, occipital neuralgia $(n=8)$ and diagnoses not specified in the ICOP $(n=23)$.

\section{Measures}

\section{Demographics and clinical characteristics}

Participants reported demographic information (eg, age, gender, ethnicity, marital status, etc.) and clinical characteristics (eg, facial pain diagnosis, duration, existence of mental health conditions, use of prescription medication for pain or mental health). This information is displayed in Table 1.

\section{Anxiety}

The PROMIS anxiety scale version $108 \mathrm{a}^{47}$ is an 8 -item questionnaire assessing the frequency and intensity of anxiety symptoms on a 1-5 Likert scale. Scores are reported as T scores with a mean of $50(\mathrm{SD}=10)$. 


\section{Depression}

The PROMIS depression scale version $108 \mathrm{~b}^{48}$ is an 8 -item questionnaire assessing the frequency and intensity of depression symptoms on a 1-5 Likert scale. Scores are reported as $\mathrm{T}$ scores with a mean of $50(\mathrm{SD}=10)$.

\section{Pain catastrophizing}

The pain catastrophizing scale (PCS) ${ }^{21}$ is a 13 -item questionnaire assessing participants' tendency to ruminate, magnify, and feel helpless in the face of pain on a $0-4$ Likert scale.

\section{Kinesiophobia}

The Tampa Kinesiophobia Scale for Temporomandibular Disorders $\left(\mathrm{TSK}_{-} \mathrm{TMD}^{35}\right.$ ) is a 12 -item questionnaire assessing fear of pain due to movement of the jaw on a 4-point Likert scale. References to "jaw" were modified to "jaw/face/neck" in order to be inclusive of broader orofacial pain conditions.

\section{Mindfulness}

The Five Facet Mindfulness Questionnaire (FFMQ-15 $5^{49}$ ) is a 15 -item questionnaire assessing different facets of mindfulness (observing, describing, acting with awareness, non-reactivity, and nonjudging) on a 5-point Likert scale.

\section{Pain intensity and pain-related disability}

The Graded Chronic Pain Scale ${ }^{50}$ is a 7 -item scale which assesses pain intensity and pain-related disability on separate subscales.

\section{Analytic Strategy}

We used SPSS version 24 for all analyses. We used multiple imputations for missing data. First, we conducted descriptive statistics and zero-order correlations. Second, to evaluate the incremental variance explained by pain catastrophizing, kinesiophobia, and mindfulness, we conducted four separate two-step hierarchical regressions for each of the criterion variables (pain intensity, pain-related disability, anxiety, and depression). For all analyses, step 1 included several theoretically relevant covariates that been previously deemed relevant to pain outcomes in orofacial pain population (ie, gender, education, employment, diagnostic category and pain duration ${ }^{11,51,52}$ ). Step 2 included the pain catastrophizing, kinesiophobia, and mindfulness scores. Unstandardized coefficient estimates and associated standard errors are reported. Model fit for each of the steps was evaluated with the $F$ statistic and an increase in variance accounted for as evidenced by a change in $R^{2}$. Squared semipartial correlations $\left(\mathrm{sr}^{2}\right)$ were used as measures of effect size, interpreted as the incremental variance added by each predictor to the regression model. Power analysis was estimated assuming a small sized effect. Thus, with power set at 0.08 $($ alpha $=0.05)$ and 8 independent variables, a sample size of 301 would be required to detect a small effect size. ${ }^{53}$

Table 2 Outcomes and Coping Variables

\begin{tabular}{|l|l|}
\hline Variable & M (SD) \\
\hline Outcomes & \\
$\quad$ Pain intensity & $59.61(21.32)$ \\
Pain-related disability (GCPS) & $50.88(31.69)$ \\
Depression & $55.30(10.46)$ \\
Anxiety & $58.25(10)$ \\
Coping variables & \\
Pain Catastrophizing (PCS) & $26.05(13.32)$ \\
Kinsesiophobia (TAMPA) & $28.26(7.21)$ \\
Mindfulness (FFMQ) & $52.75(8.47)$ \\
\hline
\end{tabular}


Table 3 Bivariate Correlations

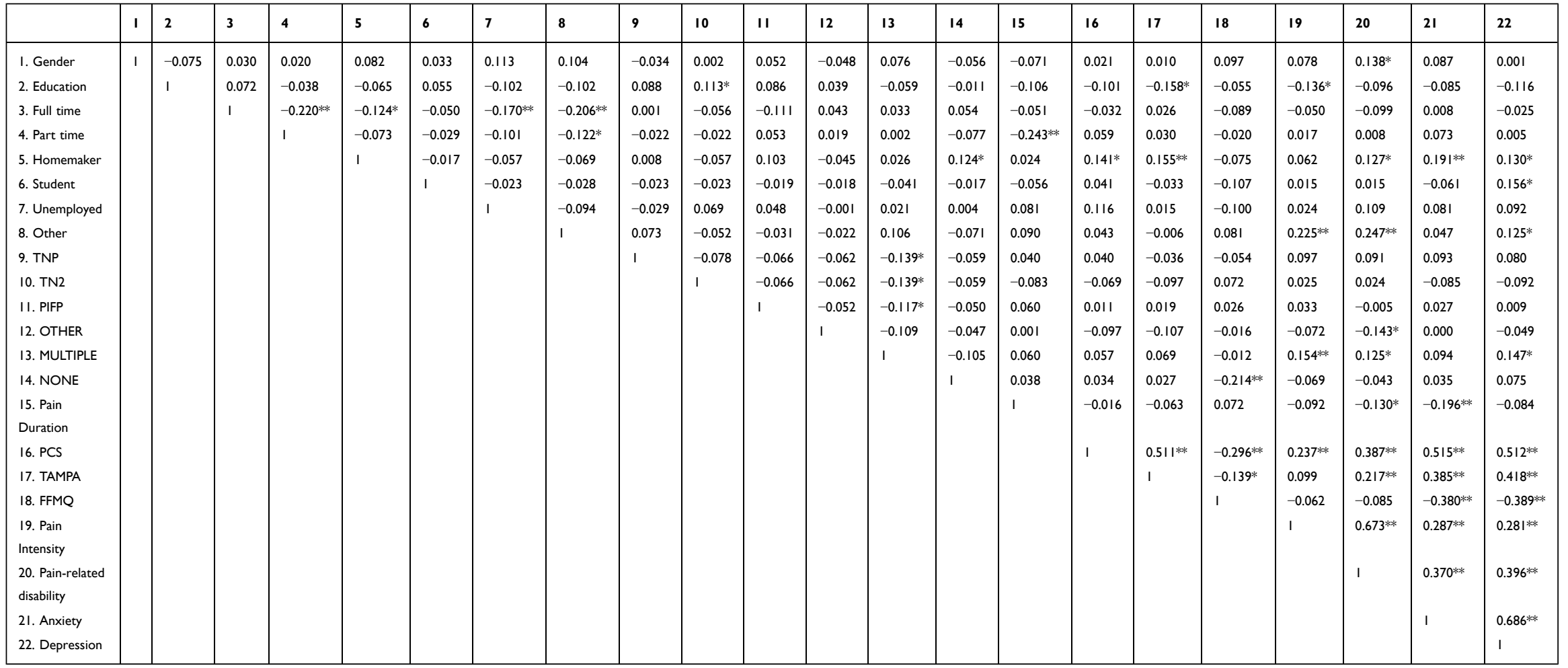

Note: *Indicates $p<0.05$; **Indicates $p<0.01$. 
Table 4 Hierarchical Regression Results

\begin{tabular}{|c|c|c|c|c|c|c|}
\hline & b & SE & $t$ & $p$ value & $95 \% \mathrm{Cl}$ for $b$ & $s r^{2}$ \\
\hline \multicolumn{7}{|l|}{ Pain intensity } \\
\hline \multicolumn{7}{|l|}{ Step I } \\
\hline Gender & 0.445 & 3.675 & 0.121 & 0.904 & $(-6.765,7.656)$ & 0.00 \\
\hline Education & -2.978 & 1.239 & -2.403 & 0.016 & $(-5.407,-0.549)$ & 0.02 \\
\hline \multicolumn{7}{|l|}{ Employment } \\
\hline Full time & 1.563 & 3.040 & 0.514 & 0.607 & $(-4.395,7.521)$ & 0.00 \\
\hline Part time & 1.500 & 4.187 & 0.358 & 0.720 & $(-6.708,9.708)$ & 0.00 \\
\hline Home maker & 7.910 & 6.471 & 1.223 & 0.222 & $(-4.772,20.593)$ & 0.00 \\
\hline Student & 9.893 & 14.842 & 0.667 & 0.505 & $(-19.197,38.983)$ & 0.00 \\
\hline Unemployed & 3.674 & 4.931 & 0.745 & 0.456 & $(-5.990,13.339)$ & 0.00 \\
\hline Other & 15.608 & 4.315 & 3.618 & 0.000 & $(7.152,24.065)$ & 0.04 \\
\hline \multicolumn{7}{|l|}{ Diagnosis category } \\
\hline TN2 & 11.015 & 4.804 & 2.293 & 0.022 & $(1.598,20.432)$ & 0.02 \\
\hline TNP & 6.677 & 4.817 & 1.386 & 0.166 & $(-2.765,16.119)$ & 0.01 \\
\hline PIFP & 8.088 & 5.591 & 1.447 & 0.148 & $(-2.87 \mid, 19.047)$ & 0.01 \\
\hline OTHER & -2.603 & 5.937 & -0.438 & 0.661 & $(-14.248,9.042)$ & 0.00 \\
\hline MULTIPLE & 8.769 & 3.201 & 2.739 & 0.006 & $(2.494,15.043)$ & 0.02 \\
\hline NONE & -2.655 & 6.082 & -0.437 & 0.662 & $(-5.812,-0.437)$ & 0.00 \\
\hline Pain duration & -2.459 & -3.124 & 1.371 & 0.023 & & 0.01 \\
\hline \multicolumn{7}{|l|}{ Step 2} \\
\hline PCS & 0.362 & 0.115 & 3.146 & 0.002 & $(0.136,0.588)$ & 0.03 \\
\hline TAMPA & -0.151 & 0.208 & -0.725 & 0.469 & $(-0.561,0.259)$ & 0.00 \\
\hline FFMQ & -0.052 & 0.173 & -0.301 & 0.764 & $(-0.395,0.291)$ & 0.00 \\
\hline \multicolumn{7}{|l|}{ Pain disability } \\
\hline \multicolumn{7}{|l|}{ Step I } \\
\hline Gender & 4.934 & 5.278 & 0.935 & 0.350 & $(-5.421,15.288)$ & 0.00 \\
\hline Education & -2.062 & 1.802 & -1.144 & 0.253 & $(-5.594,1.470)$ & 0.00 \\
\hline \multicolumn{7}{|l|}{ Employment } \\
\hline Full time & 0.229 & 4.369 & 0.052 & 0.958 & $(-8.334,8.792)$ & 0.00 \\
\hline Part time & 2.415 & 5.968 & 0.405 & 0.686 & $(-9.283,14.113)$ & 0.00 \\
\hline Homemaker & 23.849 & 9.257 & 2.576 & 0.010 & $(5.705,41.993)$ & 0.02 \\
\hline Student & 10.379 & 21.350 & 0.486 & 0.627 & $(-31.465,52.223)$ & 0.00 \\
\hline Unemployed & 17.563 & 7.068 & 2.485 & 0.013 & $(3.710,31.417)$ & 0.02 \\
\hline Other & 27.109 & 6.747 & 4.018 & 0.000 & $(13.785,40.432)$ & 0.06 \\
\hline \multicolumn{7}{|l|}{ Diagnosis category } \\
\hline TN2 & 12.478 & 6.869 & 1.817 & 0.069 & $(-0.985,25.94 I)$ & 0.01 \\
\hline TNP & 5.598 & 7.044 & 0.795 & 0.427 & $(-8.215,19.412)$ & 0.00 \\
\hline PIFP & 1.342 & 8.011 & 0.168 & 0.867 & $(-14.356,17.040)$ & 0.00 \\
\hline OTHER & $-|5.94|$ & 9.084 & -1.755 & 0.081 & $(-33.885,2.003)$ & 0.01 \\
\hline MULTIPLE & 8.200 & 4.616 & 1.776 & 0.076 & $(-0.848,17.247)$ & 0.01 \\
\hline NONE & -2.702 & 8.722 & -0.310 & 0.757 & $(-19.797,14.393)$ & 0.00 \\
\hline Pain duration & -5.823 & 1.950 & -2.986 & 0.003 & $(-9.646,-2.000)$ & 0.03 \\
\hline \multicolumn{7}{|l|}{ Step 2} \\
\hline PCS & 0.813 & 0.162 & 5.023 & 0.000 & $(0.495,1.131)$ & 0.07 \\
\hline TAMPA & 0.060 & 0.315 & 0.191 & 0.849 & $(-0.572,0.692)$ & 0.00 \\
\hline FFMQ & 0.034 & 0.224 & 0.152 & 0.879 & $(-0.406,0.474)$ & 0.00 \\
\hline \multicolumn{7}{|l|}{ Anxiety } \\
\hline Step I & & & & & & \\
\hline Gender & 0.602 & 1.736 & 0.347 & 0.729 & $(-2.809,4.013)$ & 0.00 \\
\hline Education & -0.757 & 0.627 & -1.206 & 0.229 & $(-1.996,0.482)$ & 0.01 \\
\hline Employment & & & & & & \\
\hline
\end{tabular}

(Continued) 
Table 4 (Continued).

\begin{tabular}{|c|c|c|c|c|c|c|}
\hline & $b$ & SE & $t$ & $p$ value & $95 \% \mathrm{Cl}$ for $b$ & $s r^{2}$ \\
\hline Full time & 1.714 & 1.536 & 1.115 & 0.266 & $(-1.320,4.748)$ & 0.00 \\
\hline Part time & 2.218 & 2.003 & 1.107 & 0.269 & $(-1.7|5,6.15|)$ & 0.00 \\
\hline Homemaker & 10.495 & 3.011 & 3.486 & 0.000 & $(4.594,16.397)$ & 0.04 \\
\hline Student & -6.026 & 7.612 & -0.792 & 0.430 & $(-21.088,9.037)$ & 0.00 \\
\hline Unemployed & 5.158 & 2.540 & 2.031 & 0.045 & $(0.125,10.191)$ & 0.02 \\
\hline Other & 2.997 & 2.038 & 1.471 & 0.142 & $(-0.999,6.992)$ & 0.01 \\
\hline \multicolumn{7}{|c|}{ Diagnosis category } \\
\hline TN2 & 4.815 & 2.269 & 2.122 & 0.034 & 0.01 & 0.01 \\
\hline TNP & -2.072 & 2.837 & -0.731 & $0.47 I$ & 0.00 & 0.00 \\
\hline PIFP & 2.072 & 2.752 & 0.753 & 0.452 & 0.00 & 0.00 \\
\hline OTHER & 1.439 & 2.707 & 0.532 & 0.595 & 0.00 & 0.00 \\
\hline MULTIPLE & 2.609 & 1.532 & 1.703 & 0.089 & 0.01 & 0.01 \\
\hline NONE & 2.236 & 3.862 & 0.579 & 0.570 & 0.00 & 0.00 \\
\hline Pain duration & -2.488 & 0.671 & -3.709 & 0.000 & $(-3.809,-1.168)$ & 0.05 \\
\hline \multicolumn{7}{|l|}{ Step 2} \\
\hline PCS & 0.267 & 0.051 & 5.274 & 0.000 & $(0.166,0.368)$ & 0.08 \\
\hline TAMPA & 0.201 & 0.084 & 2.392 & 0.018 & $(0.035,0.367)$ & 0.01 \\
\hline FFMQ & -0.306 & 0.067 & -4.598 & 0.000 & $(-0.438,-0.174)$ & 0.05 \\
\hline \multicolumn{7}{|l|}{ Depression } \\
\hline \multicolumn{7}{|l|}{ Step I } \\
\hline Gender & -2.257 & 1.809 & -1.248 & 0.213 & $(-5.822,1.307)$ & 0.01 \\
\hline Education & -1.116 & 0.616 & -1.812 & 0.071 & $(-2.327,0.095)$ & 0.01 \\
\hline \multicolumn{7}{|l|}{ Employment } \\
\hline Full time & 1.518 & 1.513 & 1.004 & 0.316 & $(-1.455,4.491)$ & 0.00 \\
\hline Part time & 1.331 & 2.047 & 0.650 & 0.516 & $(-2.689,5.352)$ & 0.00 \\
\hline Homemaker & 7.454 & 3.109 & 2.397 & 0.017 & $(1.357,13.55 \mathrm{I})$ & 0.02 \\
\hline Student & 23.318 & 8.369 & 2.786 & 0.008 & $(6.473,40.162)$ & 0.03 \\
\hline Unemployed & 5.691 & 3.019 & 1.885 & 0.071 & $(-0.535,11.917)$ & 0.02 \\
\hline Other & 5.507 & 2.047 & 2.690 & 0.007 & $(1.494,9.520)$ & 0.02 \\
\hline \multicolumn{7}{|c|}{ Diagnosis category } \\
\hline TN2 & $4.64 I$ & 2.450 & 1.894 & 0.060 & 0.01 & 0.01 \\
\hline TNP & -1.382 & 2.749 & -0.503 & 0.618 & 0.00 & 0.00 \\
\hline PIFP & 2.385 & 2.675 & 0.891 & 0.373 & 0.00 & 0.00 \\
\hline OTHER & -0.410 & 2.837 & -0.144 & 0.885 & 0.00 & 0.00 \\
\hline MULTIPLE & 4.200 & 1.572 & 2.672 & 0.008 & 0.02 & 0.02 \\
\hline NONE & 4.881 & 3.702 & 1.319 & 0.199 & 0.01 & 0.01 \\
\hline Pain duration & -1.457 & 0.655 & -2.223 & 0.026 & $(-2.742,-0.172)$ & 0.02 \\
\hline \multicolumn{7}{|l|}{ Step 2} \\
\hline PCS & 0.231 & 0.046 & 5.077 & 0.000 & $(0.142,0.321)$ & 0.05 \\
\hline TAMPA & 0.316 & $0.08 I$ & 3.918 & 0.000 & $(0.158,0.475)$ & 0.03 \\
\hline FFMQ & -0.298 & 0.065 & -4.567 & 0.000 & $(-0.426,-0.169)$ & 0.05 \\
\hline
\end{tabular}

Notes: For employment, all dummy coded variables represent comparisons against "retired status" as the most common category of employment. For diagnosis, all dummy coded variables represent comparisons against "trigeminal neuralgia" as the most common diagnostic category.

\section{Results}

\section{Descriptive Statistics}

Means and standard deviations for all measures are detailed in Table 2 and zero-order correlations are detailed in Table 3. Pain catastrophizing was positively correlated with all four outcome variables (pain intensity, pain-related disability, anxiety and depression; $\mathrm{rs}=0.237-0.515, \mathrm{ps}<0.001$ ). Kinesophobia was positively correlated with pain-related disability, anxiety and 
depression ( $\mathrm{rs}=0.217-0.418, \mathrm{p}<0.001$ ), but not with pain intensity. Mindfulness was negatively correlated with anxiety and depression ( $\mathrm{rs}=-0.380$ to $-0.389, \mathrm{p}<0.001$ ) but not with pain intensity or pain-related disability. The four outcome variables (pain intensity, pain-related disability, anxiety and depression) were also positively correlated with each other ( $\mathrm{rs}=0.281-0.686$, ps $<0.001$ ). Overall, participants exhibited high rates of depression and anxiety, with $67 \%$ reporting clinically meaningful symptoms of depression and $56 \%$ reporting clinically meaningful symptoms of anxiety, defined as $\geq 0.5 \mathrm{SD}$ above the general population mean. ${ }^{47,48}$

\section{Multiple Regressions}

For pain intensity, step 1 of the model was statistically significant $\left(F(14,289)=2.90, \mathrm{p}<0.0001, R^{2}=0.13\right)$. Examining the individual independent variables indicated that education $\left(\mathrm{B}=-2.978, \mathrm{SE}=1.239, \mathrm{p}=0.016, \mathrm{sr}^{2}=-0.02\right)$, an "other" employment category $\left(\mathrm{B}=15.608, \mathrm{SE}=4.310, \mathrm{p}<0.001, \mathrm{sr}^{2}=0.04\right)$, having classical trigeminal neuralgia with concomitant continuous pain $\left(\mathrm{TN} 2 ; \mathrm{B}=11.015, \mathrm{SE}=4.804, \mathrm{p}=0.022, \mathrm{sr}^{2}=0.02\right)$, having multiple orofacial pain diagnoses $\left(\mathrm{B}=8.769, \mathrm{SE}=3.201, \mathrm{p}=0.006, \mathrm{sr}^{2}=0.02\right)$, and pain duration $\left(\mathrm{B}=-3.124, \mathrm{SE}=1.371, \mathrm{p}=0.023, \mathrm{sr}^{2}=\right.$ $0.01)$ had a significant association with pain intensity. In step 2 , the model was significant $(F(17,286)=3.65, \mathrm{p}=0.013$, $\left.\Delta R^{2}=0.032\right)$. Pain catastrophizing was the only independent variable significantly associated with pain intensity, adding $3 \%$ incremental variance to the mode $\left(\mathrm{B}=0.362, \mathrm{SE}=0.115, \mathrm{p}=0.002, \mathrm{sr}^{2}=0.03\right.$; see Table 4).

For the pain-related disability outcome, step 1 was significant $\left(F(14,289)=4.22, \mathrm{p}<0.001, R^{2}=0.182\right)$. Significant independent variables included the "homemaker", "unemployed" and "other" employment categories $(\mathrm{B}=$ 23.849, $\mathrm{SE}=9.257, \mathrm{p}=0.010, \mathrm{sr}^{2}=0.02, \mathrm{~B}=17.563, \mathrm{SE}=7.068, \mathrm{p}=0.013, \mathrm{sr}^{2}=0.02$ and $\mathrm{B}=27.109, \mathrm{SE}=6.747, \mathrm{p}<$ $\left.0.001, \mathrm{sr}^{2}=0.06\right)$, and pain duration $\left(\mathrm{B}=-5.823, \mathrm{SE}=1.950, \mathrm{p}=0.003, \mathrm{sr}^{2}=0.03\right)$. For $\operatorname{step} 2(F(17,286)=13.56, \mathrm{p}<$ $0.001, \Delta R^{2}=0.10$ ), only pain catastrophizing was significantly associated with pain-related disability, adding $7 \%$ incremental variance to the model $\left(\mathrm{B}=0.813, \mathrm{SE}=0.162, \mathrm{p}<0.001, \mathrm{sr}^{2}=0.07\right.$; see Table 4).

For anxiety, the overall model was significant $\left(F(14,289)=3.04, \mathrm{p}<0.0001, R^{2}=0.13\right)$. Significant effects emerged for "homemaker" and "unemployed" employment categories $\left(\mathrm{B}=10.495, \mathrm{SE}=3.011, \mathrm{p}<0.001, \mathrm{sr}^{2}=0.04\right.$ and $\mathrm{B}=$ $5.158, \mathrm{SE}=2.540, \mathrm{p}=0.045, \mathrm{sr}^{2}=0.02$, respectively), having classical trigeminal neuralgia with concomitant continuous pain $\left(\mathrm{TN} 2 ; \mathrm{B}=4.815, \mathrm{SE}=2.269, \mathrm{p}=0.034, \mathrm{sr}^{2}=0.01\right)$ and pain duration $\left(\mathrm{B}=-2.488, \mathrm{SE}=0.671, \mathrm{p}<0.001, \mathrm{sr}^{2}=\right.$ $0.05)$. In step $2\left(F(17,286)=43.27, \mathrm{p}<0.001, \Delta R^{2}=0.27\right)$, pain catastrophizing, kinesiophobia, and mindfulness were all significantly and independently associated with anxiety $\left(\mathrm{B}=0.267, \mathrm{SE}=0.051, \mathrm{p}<0.001, \mathrm{sr}^{2}=0.08 ; \mathrm{B}=0.201, \mathrm{SE}=\right.$ $0.084, \mathrm{p}=0.018, \mathrm{sr}^{2}=0.01$ and $\mathrm{B}=-0.306, \mathrm{SE}=0.067, \mathrm{p}<0.001, \mathrm{sr}^{2}=0.05$, respectively, adding $1-8 \%$ incremental variance to the model; see Table 4).

For depression, step 1 of the model was statistically significant $\left(F(14,289)=3.73, \mathrm{p}<0.001, R^{2}=0.16\right)$. Examining the individual independent variables indicated that the "home maker", "student", and "other" employment categories (B $=7.454, \mathrm{SE}=3.109, \mathrm{p}=0.017, \mathrm{sr}^{2}=0.02 ; \mathrm{B}=23.318, \mathrm{SE}=8.369, \mathrm{p}=0.008, \mathrm{sr}^{2}=0.03$ and $\mathrm{B}=5.507, \mathrm{SE}=2.047, \mathrm{p}=$ $0.007, \mathrm{sr}^{2}=0.02$ respectively), having multiple orofacial pain diagnoses $\left(\mathrm{B}=4.200, \mathrm{SE}=1.572, \mathrm{p}=0.008, \mathrm{sr}^{2}=0.02\right)$ and pain duration $\left(\mathrm{B}=-1.457, \mathrm{SE}=0.655, \mathrm{p}=0.026, \mathrm{sr}^{2}=0.02\right)$ were significantly associated with depression. In step 2, the model was significant $\left(F(17,286)=41.82, \mathrm{p}<0.001, \Delta R^{2}=0.25\right)$. Pain catastrophizing, kinesiophobia, and mindfulness were significantly associated with depression $\left(\mathrm{B}=0.231, \mathrm{SE}=0.046, \mathrm{p}<0.001, \mathrm{sr}^{2}=0.05 ; \mathrm{B}=0.316\right.$, $\mathrm{SE}=0.081, \mathrm{p}<0.001, \mathrm{sr}^{2}=0.03$ and $\mathrm{B}=-0.298, \mathrm{SE}=0.05, \mathrm{p}<0.001, \mathrm{sr}^{2}=0.05$, respectively, adding $5-8 \%$ incremental variance to the model; see Table 4).

\section{Discussion}

Chronic orofacial pain is characterized by substantial pain-related disability and emotional distress. This study tested the association between three coping strategies (pain catastrophizing, kinesiophobia and mindfulness) and four pain-related outcomes (depression, anxiety, pain intensity, and pain-related disability), while accounting for relevant demographic and clinical variables.

Pain catastrophizing was the only coping variable that was independently associated with pain intensity and painrelated disability. This finding emphasizes the importance of addressing pain catastrophizing among individuals with orofacial pain, and its potential to aid in reducing pain intensity and pain-related disability among this population. 
While pain catastrophizing has been linked with negative pain outcomes among individuals with chronic pain ${ }^{30,54,55}$ as well as temporomandibular disorders, ${ }^{37-41}$ our finding supports the same association for other types of orofacial pain. Pain outcomes may thus benefit from interventions targeting pain catastrophizing. ${ }^{56,57}$

All three coping strategies (pain catastrophizing, kinesiophobia and mindfulness) were significantly associated with depression and anxiety. While the link between mindfulness and reduced depression and anxiety has been demonstrated in several clinical populations, ${ }^{58-61}$ including those with chronic pain, ${ }^{19,62,63}$ ours is the first study to show evidence for this association among individuals with chronic orofacial pain. The finding that all three coping strategies were independently associated with levels of depression and anxiety suggests that emotional distress among this population may be most efficiently addressed using a multifaceted intervention, incorporating skills to reduce catastrophizing, minimizing fear of pain due to movement, and cultivating a mindful approach to managing orofacial pain symptoms. Given the high rates of participants with clinically meaningful symptoms of anxiety (56\%) and depression $(67 \%)$ in our sample, addressing emotional distress is an urgent priority for this patient population.

Approximately $20 \%$ of our sample reported more than one orofacial pain diagnosis, and those that did tended to exhibit worse outcomes. This suggests that individuals with orofacial pain comorbidity may have an increased need and potential to benefit from interventions. Importantly, all three coping variables were associated with more positive outcomes, above and beyond diagnosis type in the multiple regression models. This provides preliminary support for transdiagnostic clinical interventions that address coping skills, which cut across orofacial pain conditions. Targeting pain catastrophizing, kinesiophobia, and mindfulness may therefore help improve outcomes regardless of specific pain diagnoses. Given challenges with in person treatment for individuals with orofacial pain, ${ }^{64}$ interventions delivered via web-based platforms may be a novel solution to promote adherence, engagement and improve treatment accessibility. ${ }^{65}$ Such an inclusive approach is supported by previous research indicating heterogeneous orofacial pain conditions share common experiences. ${ }^{66,67}$

Of the other demographic and clinical characteristics controlled for in the current study, employment stood out in its association with four outcome variables (depression, anxiety, pain intensity, and pain-related disability), with less favorable outcomes associated primarily with being unemployed or a homemaker in the multiple regression models. This supports previous work linking socioeconomic factors ${ }^{51}$ and specifically employment status ${ }^{11}$ with unfavorable orofacial pain outcomes, and suggests that routinely collecting employment-related information may help improve and optimize care for this patient population, ${ }^{11}$ particularly for underserved communities or those who with low socioeconomic status. ${ }^{68}$

This study has several strengths. First, the concurrent examination of the three tested coping strategies (pain catastrophizing, kinesiophobia and mindfulness) in individuals with orofacial pain is novel. This enabled us to test the relative and independent association of each strategy to several key pain-related outcomes. Further, while the concept of mindfulness has been studied in the context of chronic pain, ${ }^{24-27,62,69,70}$ to our knowledge, this is the first examination of mindfulness specifically in individuals with orofacial pain. The sample size of $>300$ participants is an additional strength, which enabled us to have sufficient statistical power to examine the association of the coping strategies above and beyond that of numerous potentially confounding demographic and clinical factors previously associated with painrelated outcomes.

Limitations of the study should also be considered. The main limitation of the study is its cross-sectional design, which precludes us from drawing causal inferences. Indeed, the association between the coping strategies and pain outcomes may be bi-directional, and factors such as anxiety and depression may have developed prior orofacial pain onset. Additionally, over two-thirds of the sample reported trigeminal neuralgia as their primary orofacial pain diagnosis, with only few cases of common diagnoses such as temporomandibular disorders (included under the "multiple diagnoses" or "other" categories). This may have impacted associations with the kinesiophobia scale (TSK-TMD), which is primarily used for musculoskeletal orofacial pain, and may limit generalizability of the findings to other orofacial pain populations to some degree. However, controlling for diagnoses in our statistical analyses may have partially reduced this risk.

Finally, all assessments, including orofacial pain diagnoses, were self-reported, which inherently carries a risk of bias. ${ }^{71}$ Longitudinal studies capturing other chronic pain and health issues and testing the effects of interventions 
targeting these coping strategies are needed to help identify the specific and potentially causal role played by such factors in pain outcomes among individuals with heterogeneous chronic orofacial pain.

\section{Conclusion}

Across people with chronic orofacial pain recruited from a national facial pain association, we found alarming rates of depression and anxiety. Higher pain catastrophizing and kinesiophobia and lower mindfulness were associated with higher depression and anxiety. Higher pain catastrophizing was associated with higher pain and disability. Results support interventions that address these three coping factors and include heterogeneous samples of people with orofacial pain.

\section{Acknowledgment}

We would like to thank the Facial Pain Association for their contribution to data collection in this study.

\section{Funding}

This study was funded by grants from the National Center for Complementary and Integrative Health to the first (1K23AT010653-01A1) and senior (1K24AT011760-01) authors.

\section{Disclosure}

The authors declare that they have no conflicts of interest.

\section{References}

1. Aggarwal VR, Lovell K, Peters S, et al. Psychosocial interventions for the management of chronic orofacial pain. Cochrane Database Syst Rev. 2011;11. doi:10.1002/14651858.cd008456.pub2

2. Aggarwal VR, Macfarlane GJ, Farragher TM, McBeth J. Risk factors for onset of chronic oro-facial pain - results of the North Cheshire oro-facial pain prospective population study. Pain. 2010;149:354-359. doi:10.1016/j.pain.2010.02.040

3. Macfarlane TV, Blinkhorn AS, Davies RM, Kincey J, Worthington HV. Oro-facial pain in the community: prevalence and associated impact. Community Dent Oral Epidemiol. 2002;30:52-60. doi:10.1034/j.1600-0528.2002.300108.x

4. National Institute of Dental and Craniofacial Research. Facial Pain; 2018. Available from: https://www.nidcr.nih.gov/research/data-statistics/facialpain. Accessed January 18, 2022.

5. Crombez G, Eccleston C, Van Damme S, Vlaeyen JWS, Karoly P. Fear-avoidance model of chronic pain: the next generation. Clin J Pain. 2012;28:475-483. doi:10.1097/AJP.0b013e3182385392

6. Zale EL, Lange KL, Fields SA, Ditre JW. The relation between pain-related fear and disability: a meta-analysis. J Pain. 2013;14:1019-1030. doi:10.1016/j.jpain.2013.05.005

7. Kamper SJ, Apeldoorn AT, Chiarotto A, et al. Multidisciplinary biopsychosocial rehabilitation for chronic low back pain. Cochrane Database Syst Rev. 2014;9. doi:10.1002/14651858.CD000963.pub3

8. Kotiranta U, Suvinen T, Forssell H. Tailored treatments in temporomandibular disorders: where are we now? A systematic qualitative literature review. J Oral Facial Pain Headache. 2014;28:28-37. doi:10.11607/jop.1121

9. Suvinen TI, Reade PC, Kemppainen P, Könönen M, Dworkin SF. Review of aetiological concepts of temporomandibular pain disorders: towards a biopsychosocial model for integration of physical disorder factors with psychological and psychosocial illness impact factors. Eur J Pain. 2005;9 (6):613. doi:10.1016/j.ejpain.2005.01.012

10. Gustin SM, Wilcox SL, Peck CC, Murray GM, Henderson LA. Similarity of suffering: equivalence of psychological and psychosocial factors in neuropathic and non-neuropathic orofacial pain patients. Pain. 2011;152(4):825-832. doi:10.1016/j.pain.2010.12.033

11. Bhalang K, Steiger B, Lukic N, et al. The pain-to-well-being relationship in patients experiencing chronic orofacial pain. Front Neurol. $2020 ; 11$. doi:10.3389/fneur.2020.557415

12. Castro AR, Siqueira SRDT, Perissinotti DMN, Teixeira MJ, Siqueira JTT. Emotional aspects of chronic orofacial pain and surgical treatment. Int J Surg. 2009;7:196-199. doi:10.1016/j.ijsu.2009.02.002

13. Manfredini D, Winocur E, Ahlberg J, Guarda-Nardini L, Lobbezoo F. Psychosocial impairment in temporomandibular disorders patients. RDC/ TMD axis II findings from a multicentre study. J Dent. 2010;38:765-772. doi:10.1016/j.jdent.2010.06.007

14. Braunsteiner NE, Vickers ER, Toole BM, Braunsteiner J. Psychosocial factors and addiction in chronic orofacial neuropathic pain. Aust Endod J. 2018;44:148-158. doi:10.1111/aej.12254

15. Raggi A, Giovannetti AM, Quintas R, et al. A systematic review of the psychosocial difficulties relevant to patients with migraine. $J$ Headache Pain. 2012;13:595-606. doi:10.1007/s10194-012-0482-1

16. Browning S, Hislop S, Scully C, Shirlaw P. The association between burning mouth syndrome and psychosocial disorders. Oral Surg Oral Med Oral Pathol. 1987;64:171-174. doi:10.1016/0030-4220(87)90085-5

17. De Das S, Vranceanu AM, Ring DC. Contribution of kinesophobia and catastrophic thinking to upper-extremity-specific disability. $J$ Bone Joint Surg Ser A. 2013;95:76-81. doi:10.2106/JBJS.L.00064

18. Greenberg J, Mace RA, Popok PJ, et al. Psychosocial correlates of objective, performance-based, and patient-reported physical function among patients with heterogeneous chronic pain. J Pain Res. 2020;13:2255-2265. doi:10.2147/JPR.S266455 
19. Grunberg VA, Mace RA, Bannon SM, et al. Mechanisms of change in depression and anxiety within a mind-body activity intervention for chronic pain. J Affect Disord. 2021;292:534-541. doi:10.1016/j.jad.2021.05.069

20. Dong H-J, Gerdle B, Bernfort L, Levin L-Å, Dragioti E. Pain catastrophizing in older adults with chronic pain: the mediator effect of mood using a path analysis approach. J Clin Med. 2020;9:2073. doi:10.3390/jcm9072073

21. Sullivan MJL, Bishop SR, Pivik J. The Pain Catastrophizing Scale: development and validation. Psychol Assess. 1995;7:524-532. doi:10.1037/ 1040-3590.7.4.524

22. Woby SR, Roach NK, Urmston M, Watson PJ. Psychometric properties of the TSK-11: a shortened version of the Tampa Scale for Kinesiophobia. Pain. 2005;117:137-144. doi:10.1016/j.pain.2005.05.029

23. Kabat-Zinn J. Wherever You Go, There You Are: Mindfulness Meditation in Everyday Life. Hyperion; 1994.

24. Nathan HJ, Poulin P, Wozny D, et al. Randomized trial of the effect of mindfulness-based stress reduction on pain-related disability, pain intensity, health-related quality of life, and A1C in patients with painful diabetic peripheral neuropathy. Clin Diabetes. 2017;35:294-304. doi:10.2337/cd170077

25. Davoudi M, Allame Z, Niya RT, Taheri AA, Ahmadi SM. The synergistic effect of vitamin D supplement and mindfulness training on pain severity, pain-related disability and neuropathy-specific quality of life dimensions in painful diabetic neuropathy: a randomized clinical trial with placebo-controlled. J Diabetes Metab Disord. 2021;20:49-58. doi:10.1007/s40200-020-00700-3

26. Cherkin DC, Sherman KJ, Balderson BH, et al. Effect of mindfulness-based stress reduction vs cognitive behavioral therapy or usual care on back pain and functional limitations in adults with chronic low back pain: a randomized clinical trial. J Am Med Assoc. 2016;315:1240-1249. doi:10.1001/jama.2016.2323

27. Esmer G, Blum J, Rulf J, Pier J. Mindfulness-based stress reduction for failed back surgery syndrome: a randomized controlled trial. $J$ Am Osteopath Assoc. 2010;110:646-652.

28. Morone NE, Rollman BL, Moore CG, Li Q, Weiner DK. A mind-body program for older adults with chronic low back pain: results of a pilot study. Pain Med. 2009;10:1395-1407. doi:10.1111/j.1526-4637.2009.00746.x

29. Swinkels-Meewisse IEJ, Roelofs J, Oostendorp RAB, Verbeek ALM, Vlaeyen JWS. Acute low back pain: pain-related fear and pain catastrophizing influence physical performance and perceived disability. Pain. 2006;120:36-43. doi:10.1016/j.pain.2005.10.005

30. Severeijns R, Vlaeyen JWS, Van Den Hout MA, Weber WEJ. Pain catastrophizing predicts pain intensity, disability, and psychological distress independent of the level of physical impairment. Clin J Pain. 2001;17:165-172. doi:10.1097/00002508-200106000-00009

31. Ramírez-Maestre C, Esteve R, Ruiz-Párraga G, Gómez-Pérez L, López-Martínez AE. The key role of pain catastrophizing in the disability of patients with acute back pain. Int J Behav Med. 2017;24:239-248. doi:10.1007/s12529-016-9600-9

32. Varallo G, Scarpina F, Giusti EM, et al. The association of kinesiophobia and pain catastrophizing with pain-related disability and pain intensity in obesity and chronic lower-back pain. Brain Sci. 2021;11:1-8. doi:10.3390/brainsci11060684

33. Luque-Suarez A, Martinez-Calderon J, Falla D. Role of kinesiophobia on pain, disability and quality of life in people suffering from chronic musculoskeletal pain: a systematic review. Br J Sports Med. 2019;53:554-559. doi:10.1136/bjsports-2017-098673

34. Lundberg MKE, Larsson M, Östlund H, Styf J. Kinesiophobia among patients with musculoskeletal pain in primary healthcare. $J$ Rehabil Med. 2006;38:37-43. doi:10.1080/16501970510041253

35. Visscher CM, Ohrbach R, Van Wijk AJ, Wilkosz M, Naeije M. The Tampa Scale for Kinesiophobia for Temporomandibular Disorders (TSK-TMD). Pain. 2010;150:492-500. doi:10.1016/j.pain.2010.06.002

36. Lira MR, Da silva RR, Bataglion C, et al. Multiple diagnoses, increased kinesiophobia? - Patients with high kinesiophobia levels showed a greater number of temporomandibular disorder diagnoses. Musculoskelet Sci Pract. 2019;44:102054.

37. Jang -H-H, Kim M-E, Kim H-K. Pain catastrophizing mediates the effects of psychological distress on pain interference in patients with orofacial pain: a Cross-Sectional Study. J Oral Facial Pain Headache. 2018;32:409-417. doi:10.11607/ofph.2067

38. Reiter S, Eli I, Mahameed M, et al. Pain catastrophizing and pain persistence in temporomandibular disorder patients. $J$ Oral Facial Pain Headache. 2018;32:309-320. doi:10.11607/ofph.1968

39. Turner JA, Dworkin SF, Mancl L, Huggins KH, Truelove EL. The roles of beliefs, catastrophizing, and coping in the functioning of patients with temporomandibular disorders. Pain. 2001;92:41-51. doi:10.1016/S0304-3959(00)00469-3

40. Velly AM, Look JO, Carlson C, et al. The effect of catastrophizing and depression on chronic pain - a prospective cohort study of temporomandibular muscle and joint pain disorders. Pain. 2011;152:2377-2383. doi:10.1016/j.pain.2011.07.004

41. Turner JA, Brister H, Huggins K, et al. Catastrophizing is associated with clinical examination findings, activity interference, and health care use among patients with temporomandibular disorders. J Orofac Pain. 2005;19:291-300.

42. Gil-Martínez A, Grande-Alonso M, López-de-uralde-villanueva I, et al. Chronic Temporomandibular disorders: disability, pain intensity and fear of movement. J Headache Pain. 2016;17. doi:10.1186/s10194-016-0690-1

43. Durham J, Raphael KG, Benoliel R, et al. Perspectives on next steps in classification of oro-facial pain - part 2: role of psychosocial factors. J Oral Rehabil. 2015;42:942-955. doi:10.1111/joor.12329

44. Erdogan O, Ramsey A, Uyanik JM, Gibbs JL, Burns LE. Outcomes of referrals from endodontic to orofacial pain specialists: a retrospective cohort study. Clin Exp Dent Res. 2021. doi:10.1002/cre2.497

45. Badel T, Ćimić S, Munitić M, et al. Clinical view of the temporomandibular joint disorder. Acta Clin Croat. 2014;53:462-470.

46. International Classification of Orofacial Pain, 1st edition (ICOP). Cephalalgia. 2020;40:129-221. doi:10.1177/0333102419893823

47. A brief guide to the PROMIS anxiety instruments. Outcomes measurement information system; 2015. Available from: http:/www.healthmeasures. net/images/PROMIS/manuals/PROMIS_Depression_Scoring_Manual.pdf. Accessed January 18, 2022.

48. A brief guide to the PROMIS depression instruments. Patient reported outcomes measurement information system; 2015. Available from: http:// www.healthmeasures.net/images/PROMIS/manuals/PROMIS_Depression_Scoring_Manual.pdf. Accessed January 18, 2022.

49. Gu J, Strauss C, Crane C, et al. Examining the factor structure of the 39 -item and 15 -item versions of the five Facet mindfulness questionnaire before and after mindfulness-based cognitive therapy for people with recurrent depression. Psychol Assess. 2016;28:791-802. doi:10.1037/ pas0000263

50. Smith BH, Penny KI, Purves AM, et al. The chronic pain grade questionnaire: validation and reliability in postal research. Pain. $1997 ; 71: 141-147$. doi:10.1016/S0304-3959(97)03347-2 
51. Van Deun L, De witte M, Goessens T, et al. Facial pain: a comprehensive review and proposal for a pragmatic diagnostic approach. Eur Neurol. 2020;83(1):5-16. doi:10.1159/000505727

52. Mačianskyte D, Janužis G, Kubilius R, Adomaitiene V, Ščiupokas A. Associations between chronic pain and depressive symptoms in patients with trigeminal neuralgia. Medicina (B Aires). 2011;47(7):386-392. doi:10.3390/medicina47070055

53. Cohen J. Statistical Power Analysis for the Behavioral Sciences. Hillsdale, NJ: Lawrence Earlbaum Associates; 1988.

54. Vowles KE, McCracken LM, Eccleston C. Processes of change in treatment for chronic pain: the contributions of pain, acceptance, and catastrophizing. Eur J Pain. 2007;11:779-787. doi:10.1016/j.ejpain.2006.12.007

55. Turner JA, Jensen MP, Warms CA, Cardenas DD. Catastrophizing is associated with pain intensity, psychological distress, and pain-related disability among individuals with chronic pain after spinal cord injury. Pain. 2002;98:127-134. doi:10.1016/S0304-3959(02)00045-3

56. Daniel H, Poole J, Klein H, Huang C, Zakrzewska J. Cognitive behavioral therapy for patients with trigeminal neuralgia: a feasibility study. J Oral Facial Pain Headache. 2021;35:30-34. doi:10.11607/ofph.2664

57. Simmons LA, Williams H, Silva S, Keefe F, Tanabe P. Acceptability and feasibility of a mindfulness-based intervention for pain catastrophizing among persons with sickle cell disease. Pain Manag Nurs. 2019;20:261-269. doi:10.1016/j.pmn.2018.10.002

58. Hofmann SG, Sawyer AT, Witt AA, Oh D. The effect of mindfulness-based therapy on anxiety and depression: a meta-analytic review. $J$ Consult Clin Psychol. 2010;78(2):169-183. doi:10.1037/a0018555

59. Toneatto T, Nguyen L. Does mindfulness meditation improve anxiety and mood symptoms? A review of the controlled research. Can J Psychiatry. 2007;52(4):260-266. doi:10.1177/070674370705200409

60. Piet J, Würtzen H, Zachariae R. The effect of mindfulness-based therapy on symptoms of anxiety and depression in adult cancer patients and survivors: a systematic review and meta-analysis. J Consult Clin Psychol. 2012;80:1007-1020. doi:10.1037/a0028329

61. Goldberg SB, Tucker RP, Greene PA, et al. Mindfulness-based interventions for psychiatric disorders: a systematic review and meta-analysis. Clin Psychol Rev. 2018;59:52-60. doi:10.1016/j.cpr.2017.10.011

62. Chiesa A, Serretti A. Mindfulness-based interventions for chronic pain: a systematic review of the evidence. J Altern Complement Med. 2011;17:83-93. doi:10.1089/acm.2009.0546

63. Veehof MM, Oskam MJ, Schreurs KMG, Bohlmeijer ET. Acceptance-based interventions for the treatment of chronic pain: a systematic review and meta-analysis. Pain. 2011;152:533-542. doi:10.1016/j.pain.2010.11.002

64. Sangalli L, Fernandez-Vial D, Moreno-Hay I, Boggero I. Telehealth increases access to brief behavioral interventions in orofacial pain clinic during COVID-19 pandemic: a retrospective study. Pain Med. 2021. doi:10.1093/pm/pnab295

65. Lester EG, Hopkins SW, Popok PJ, Vranceanu AM. Adaptation of a live video mind-body program to a web-based platform for English-speaking adults with neurofibromatosis (NF): protocol for the NF-Web study. JMIR Res Protoc. 2021;10(6):e27526. doi:10.2196/27526

66. Woda A, Tubert-Jeannin S, Bouhassira D, et al. Towards a new taxonomy of idiopathic orofacial pain. Pain. 2005;116(3):396-406. doi:10.1016/j. pain.2005.05.009

67. Peters S, Goldthorpe J, McElroy C, et al. Managing chronic orofacial pain: a qualitative study of patients', doctors', and dentists' experiences. $B r$ $J$ Health Psychol. 2015;20:777-791. doi:10.1111/bjhp.12141

68. Fuentes M, Hart-Johnson T, Green CR. The association among neighborhood socioeconomic status, race and chronic pain in black and white older adults. J Natl Med Assoc. 2007;99:1160-1169.

69. Kabat-Zinn J, Lipworth L, Burney R. The clinical use of mindfulness meditation for the self-regulation of chronic pain. $J$ Behav Med. 1985;8:163-190. doi:10.1007/BF00845519

70. Hilton L, Hempel S, Ewing BA, et al. Mindfulness meditation for chronic pain: systematic review and meta-analysis. Ann Behav Med. 2017;51:199-213. doi:10.1007/s12160-016-9844-2

71. Arnold HJ, Feldman DC. Social desirability response bias in self-report choice situations. Acad Manag J. 1981;24:377-385.

Journal of Pain Research

Dovepress

\section{Publish your work in this journal}

The Journal of Pain Research is an international, peer reviewed, open access, online journal that welcomes laboratory and clinical findings in the fields of pain research and the prevention and management of pain. Original research, reviews, symposium reports, hypothesis formation and commentaries are all considered for publication. The manuscript management system is completely online and includes a very quick and fair peer-review system, which is all easy to use. Visit http://www.dovepress.com/testimonials.php to read real quotes from published authors.

Submit your manuscript here: https://www.dovepress.com/journal-of-pain-research-journal 